\title{
3 Research Soure \\ First Report Of IgE Sensitization To Anisakis Simplex In a Healthy Population in Colombia
}

Jenniffer Alejandra Castellanos Garzon ( $\sigma$ jacastellanos@uceva.edu.co )

Central University of Valle del Cauca

Florencio Ubeira

University of Santiago de Compostela

Maria Pustovrh

Universidad del Valle

Liliana Salazar

Universidad del Valle

Alvaro Daschner

Hospital Universitario de La Princesa

Carmen Cuellar

Complutense University of Madrid

\section{Research Article}

Keywords: Anisakis simplex, lgE, recombinant allergens, allergy, nematodes, fish consumption.

Posted Date: August 4th, 2021

DOI: https://doi.org/10.21203/rs.3.rs-763329/v1

License: (c) (i) This work is licensed under a Creative Commons Attribution 4.0 International License.

Read Full License 


\section{Abstract}

The anisakiasis is little known in Colombia and rarely diagnosed. However, reports of fish parasitized by anisakid larvae in South America are increasing. The objective was determine the prevalence of sensitization to Anisakis simplex in a healthy population in Colombia. Cross-sectional survey of 150 volunteers from Universidad del Valle's community, Cali, Colombia. Past medical history, including eating habits associated with fish consumption was assessed. Prevalence of IgE antibodies was determined by the ELISA-Trisakis 170 kit for the recombinant allergens Ani s 1 and Ani s 7. Two sera (1.3\%) of blood tested were positive to the Ani s 7 antigen, while for Ani s 1 all sera were negative. This research is the first exploratory study on Anisakis prevalence conducted in Colombia, the results do not indicate a major problem. Nevertheless, more epidemiological studies are needed.

\section{Introduction}

It is widely accepted that diets rich in fish have beneficial effects in the prevention of cardiovascular diseases (1). However, fish consumption varies with culinary traditions along the world and is especially dependent of the geographical position of countries and regional availability of fishes. According to the Food and Agriculture Organization of the United Nations (FAO), the average annual fish consumption in Colombia is particularly low, with only $4.73 \mathrm{~kg}$ per capita, which contrast with countries as Spain (38 $\mathrm{kg} /$ year), Japan (54 kg/year), and even the mean consumption in Latin America (18 kg/year) (2). Yet globalization has facilitated the introduction of Mediterranean and Asian foods in diets worldwide, resulting in fish consumption increasing in countries with little or no tradition of it (3). Like in other parts of world, several studies in Colombia reported the presence of nematodes of the family Anisakidae in fish for human consumption, both in waters of the Atlantic Ocean and the Pacific Ocean (4-8), which represents a potential risk for human infections, particularly when consumed raw, semi-raw, in sushi, salted, or marinated.

Although only a clinical case of Anisakis infection has been reported in Colombia (9) until now, the accumulated experience in other countries revealed that Anisakis infections are frequently misdiagnosed, mainly when subclinical cases not reporting the typical symptoms as urticaria, angioedema, gastrointestinal allergies and/or anaphylaxis are present $(10,11)$. Indeed, this form of anisakiasis can be present a prevalence of $12 \%$ in some populations $(12,13)$. By this reason, Moneo et al. $(11)$ suggested that, from a public health perspective, any epidemiologic study on Anisakis infections should include the group of sensitized asymptomatic patients, i.e., individuals with a high titer of anti-Anisakis IgE who likely presented an undiagnosed or subclinical gastric anisakiasis without allergic symptoms.

To detect sensitized asymptomatic patients in a population, serological methods with a combination of target allergens can be used providing they are specific and selected to cover together $100 \%$ of infected subjects $(13,14)$. A combination of recombinant Ani s 1 and Ani s 7 allergens recognized seems to meet these criteria as it was reported that near $100 \%$ of patients who have been sensitized during an Anisakis infection produced IgE antibodies to at least one of these allergens $(15,16)$. Therefore, the objective of 
this study was to determine the IgE sensitization of the parasite Anisakis simplex in a healthy population in Colombia in which fish consumption habits were also investigated in order to enable comparisons with the results of the seropositive subjects.

\section{Materials And Methods \\ Study population}

One hundred and fifty healthy volunteers from members of the teaching and student community of the Universidad del Valle, San Fernando campus, in Cali, Colombia participated in the study. All provided signed informed consent.

\section{Survey}

A survey was conducted on all volunteers to determine their fish and shellfish consumption and general medical history, following the protocol proposed by Puente et al. in 2008 and Castellanos-Garzón et al. in $2019(2,12)$. The survey comprised 28 questions: six on general information, 15 on eating habits associated with the consumption of fish/shellfish with multiple choice options, and seven open questions about medical history. The questions included the frequency of consumption of specific food items per month, their place of consumption (restaurants/home), form of consumption and/or preparation (canned, raw, salted), the species of fish consumed, and participants' personal medical history. The survey was previously validated by means of a pilot on 44 volunteers from the same study population.

Inclusion criteria: (a) Being of legal age; (b) consumption of fish or shellfish; (c) a willingness to provide the requested blood serum sample; (d) the ability to provide informed consent, and; (e) the ability and willingness to answer the survey.

Exclusion criteria: a) At the time of blood sampling, one sample was insufficient or had hemolysis. b) A request for withdrawal from the study was made by the participant.

\section{Sampling}

By means of venipuncture, a $10 \mathrm{ml}$ blood sample was taken from each volunteer and centrifuged. The serum obtained was then stored and preserved at $-20^{\circ} \mathrm{C}$.

\section{Determination of IgE antibodies to rAni s 1 and t-Ani s 7 allergens}

Anti-Ani s 1 and anti-Ani s 7 lgE determinations were done using the Trisakis 170 kit developed at the Universidad de Santiago de Compostela (Santiago de Compostela, Spain) using the extended protocol included with the kit. The results of each serum were calculated by subtracting the value of the corresponding negative control from the OD obtained for the wells coated with the rAni s 1 and t-Ani s 7 
allergens. The samples were considered positive when the calculated absorbance was greater than the cut-off points of the rAni s 1 and t-Ani s 7 , being 0.09 and 0.05 respectively $(15,17)$.

\section{Statistical analysis}

The SPSS program, version 15.0, was employed and a descriptive analysis was carried out to establish frequencies and averages. The Kolmogoroff Smirnoff test was applied to determine the distribution of the data. The quantitative variables were: frequency of fish intake, canned fish, raw fish, salted fish, consumption of shellfish and consumption of fish in restaurants. These results were related to the medical history associated with allergies. For each variable, the median and interquartile range were calculated and compared using the Mann-Whitney test. Variables with a P value of $\leq 0.05$ were considered significant. The laboratory tests were analyzed with the GraphPad Prism 6 program. The qualitative variables are described in the form of frequency/total and in percentages, and the quantitative variables as mean \pm standard deviation. Comparison between quantitative data between two groups was performed with the Student's t-test or Mann Whitney's $U$, according to the distribution of the data. Values of $\mathrm{P}<0.05$ were considered statistically significant.

\section{Results And Discussion}

The participants of the present investigation were all residing in Cali, a city near the main fishing port of Buenaventura on the Pacific coast - a region which supplies fish and shellfish to the interior of Colombia (18). However, the lack of dock, port processing and refrigeration services is reflected in the inadequate handling of fresh and frozen fish (19) which favors the survival of the agents which cause parasitic diseases such as anisakid nematodes. The presence of fish caught in Buenaventura parasitized with anisakid nematodes as referenced by several authors, is of concern, since these parasites not only produce digestive or extraintestinal symptoms associated with consuming raw fish but also cause allergic symptoms (20).

Of the 150 participants, 84 were women (56\%) and 66 men (44\%), with ages ranging between 18-67 for women and 18-61 for men. The median consumption of fish was three times a month [interquartile range (IQR) 2-5], the consumption of canned fish (tuna and sardines) was twice a month [IQR 1-3] and the consumption of raw fish (salted/marinated) and seafood was once a month [IQR 0-1.25]. In this study, the main dietary habits associated with the risk of anisakiasis in a healthy population were investigated and it was found that $87 \%$ of the participants consume raw or semi-raw fish (sushi, marinated or salted), a percentage slightly higher than that reported for University students from Bucaramanga (74.2\%) (21). Also, nineteen percent referred to eat raw fish in restaurants. At home, the preferred form of consumption was fried $(70 \%)$, while $7 \%$ consumed it raw, marinated or salted.

The five most commonly consumed fish species were tilapia (Oreochromis sp.) with $31 \%$, tuna (Thunnus sp.) $26 \%$, salmon (Salmo sp.) 17\%, trout (Oncorhynchus mykiss) 10\%, and snapper (Lutjanus sp.) with $3 \%$. Also, research carried out in capital in the interior of the country $(21,22)$ indicates that the general population has a preference for consuming the same species of fish included in this study. However, an 
association cannot be made between these species and anisakiasis as some of these are freshwater species. However, in Colombia, several studies are known that record fish for human consumption parasitized by nematodes of the family Anisakidae in the Atlantic Ocean and Anisakis sp. Anisakis physeteris and Pseudoterranova decipiens in the Pacific Ocean $(4-6,23)$.

Regarding seafood, the participants preferred to consume either shrimp (55\%) or langoustine (4\%). Eighty-seven percent of the participants indicated that their fish products had been frozen before consumption and $13 \%$ stated that they preferred to have it refrigerated.

Participants' medical histories show that $11 \%$ reported having experienced at some point digestive problems associated with the consumption of fish or shellfish, $12 \%$ had allergic-type symptoms, and $2 \%$ reported having presented both allergic and digestive symptoms. With regard to food-type allergies, $11 \%$ reported being allergic to some type of food. Four percent of respondents reported being allergic to shellfish, $27 \%$ reported some type of respiratory allergy and $47 \%$ reported dust mite allergies. The fact that only two patients showed IgE antibodies to the Anisakis allergens suggest these symptoms are not due to infections by Anisakis

The comparative study of the analyzed variables showed that participants who consume salted fish have a greater probability of suffering from hives $(P<0.03)$, of being allergic to mites $(P<0.02)$ and of presenting allergies to some type of food $(P<0.04)$. Regarding seafood consumption, a positive association was observed with the probability of presenting urticaria $(P<0.04)$. In addition, in relation to the frequency of fish consumption per month, the analysis determined that the higher the intake, the greater the probability of suffering from hives $(P<0.001)$ and a trend towards significance with regard to mite allergy $(P=0.063)$.

Furthermore, as only two cases were positive to Anisakis allergens, we could not find a correlation between specific IgE antibodies and the frequency of fish consumption.

Using the Trisakis $170 \mathrm{kit}$, it was found that only two sera (1.3\%) showed positive levels of IgE antibodies against the tAni s 7 allergen. Moreover, the data showed that the OD values of the two positive sera (OD = 0.064 and 0.055 , respectively) are near the cut-off value of the assay for Ani s $7(O D=0.05)$. Due to the low prevalence observed, as expected, no significant statistical differences were observed between Ani s 7 sensitization and the parameters of fish consumption. In addition, both positive subjects reported to consume canned fish (tuna) between three and eight times a month, shellfish, and to have preference of consuming fish either fried, steamed, oven-baked or breaded. Interestingly, one participant (IgE OD value $=0.055$ ) reported to consume raw fish. Nevertheless, none of the two positive cases experienced recent digestive or allergic symptoms associated with the consumption of fish or shellfish. Also, they did not suffer from any type of food or respiratory allergy, and nor had they been diagnosed with any parasitosis along their life.

The $1.3 \%$ of positivity to Anisakis obtained in our study can be considered as moderate as this was lower than the $7 \%$ reported in endemic countries (11), similar to the values obtained in a recent study in Croatia 
(13) testing workers from a fish processing plant (1.8\%), and higher than the $0.2 \%$ reported by Lin et al. (24) in Norway, a country with one of the highest consumptions of fish worldwide. Low to moderate values of IgE sensitization to Anisakis allergens in a population with high fish consumption confirm that fish consumption per se is not the main risk factor for sensitization $(25,26)$. In contrast, positive correlation between specific IgE to Anisakis allergens and consumption of raw fish were observed in several regions of Europe. In this sense, a high prevalence of $12.4 \%$ and $1.4 \%$ were observed in Madrid (Spain) and Sicily (Italy), both regions with high consumption of fish/and raw fish), which contrast with the low prevalence in Galicia (NW Spain) $0.43 \%$, a region of high consumption of fish but low consumption of raw fish $(12,27,28)$. However, as only two positive cases were recorded in our study, no association could be obtained with the consumption of fish in our study, although the result with the smaller IgE value corresponds to a person who declared consuming raw fish.

Regarding the results against the Ani s 1 allergen, no volunteer tested positive. These results are in accordance with the literature $(16,29)$, taking into account that a positive IgE response to Ani $s$ is mainly associated with symptomatic patients, and more specifically with allergic anisakiasis, a condition defined as an active infection by Anisakis larvae. These results are comparable with the seroprevalence reported in Norway (24) where, in a population with similar characteristics, all sera tested also negative to Ani s 1.

In summary, we conducted the first exploratory study to assess the prevalence of Anisakis infections in volunteers from a Colombian population. However, due to the limited number of subjects analyzed and the low number of positive cases observed (1.3\%), further studies are required to know with more precision the seroprevalence and the risk factors implicated.

\section{Declarations}

\section{Conflicts of interest}

The authors have no conflicts of interest to declare.

\section{Financial support}

This study was financed by the Department for Science, Technology \& Innovation in Colombia (COLCIENCIAS, Official call \#567), the Iberoamerican Association for Postgraduate Universities (AUIP), and the Colombian Professional Council of Biology (CPBiol).

\section{Declaration of submission and verification}

The authors declare that this work here has not been published previously, nor is it under consideration for publication elsewhere. All authors have approved the final version of this manuscript.

The authors confirm that all methods were carried out in accordance with relevant guidelines and regulations 
Acknowledgments: We express our gratitude to the TEBLAMI Research Group, the Universidad del Valle and its students and teachers for all their support and collaboration.

Sponsorships: This study was financed by the Department for Science, Technology \& Innovation in Colombia (COLCIENCIAS, Official call \#567), the Iberoamerican Association for Postgraduate Universities (AUIP), and the Colombian Professional Council of Biology (CPBiol).

Ethics declatarations: A cross-sectional study was carried out with the approval of the Institutional Review Committee of Human Ethics in the Faculty of Health at the Universidad del Valle through Act No. 015-015. All provided signed informed consent.

\section{References}

1. Watanabe, Y. \& Tatsuno, I. Prevention of Cardiovascular Events with Omega-3 Polyunsaturated. Off J Japan Atheroscler Soc Asian Pacific Soc Atheroscler Vasc Dis, 26, 183-198 (2019).

2. Castellanos-garzón, J. A., Daschner, Ã., Pustovrh, M. C. \& Cuellar, C. Characteristics related to fish consumption and the risk of ichthyozoonosis in a Colombian population. Rev Salud Pública, 21 (6), 1-8 (2019).

3. Maniscalchi Badaoui, M. T. et al. Larvas Anisakidae en peces del género Mugil comercializados en mercados de la región costera nor-oriental e insular de Venezuela. Saber, Univ Oriente, Venez. 2015;27(1):30-8.

4. Castellanos, J. A., Santana-piñeros, A. M., Mercado, R. \& Peña, S. Presence of anisakid larvae in commercial fishes landed in the Pacific coast of Ecuador and Colombia. 2018;22(4):206-12.

5. Castellanos, J. A., Tangua, A. R., Mercado, R. \& Salazar, L. First reporting of Anisakis sp. in the Armed Snook fish (Centropomus armatus) caught and commercialized in Buenaventura, Colombia.Infectio. 2018;22(3).

6. Castellanos, J. A., Tangua, A. R. \& Salazar, L. Anisakidae nematodes isolated from the flathead grey mullet fish (Mugil cephalus) of Buenaventura, Colombia. Int J Parasitol Parasites Wildl, 6, 265-270 (2017).

7. Oliviero Verbel, J., Baldiris Avila, R., Caballeor Gallardo, K. \& Pacheco Londoño, Y.. Nemátodos de la Familia Anisakidae en Especies Ícticas de la Bahía de Cartagena y el Canal del Dique. In: OliveroVerbel J, editor. Parásitos en peces colombianos: Están enfermando nuestros ecosistemas. Editoral U. Cartagena:Editorial Universidad de Cartagena; 2008.p. 63-84.

8. Olivero Verbel, J., Caballero-Gallardo, K. \& Arroyo-Salgado, B. Nematode infection in fish from Cartagena Bay, North of Colombia. Vet Parasitol, 177 (1-2), 119-126 (2011).

9. Patiño, J. A. \& Olivera, M. J. Anisakiasis gastro-alérgica, primera descripción de un caso en Colombia y revisión bibliográfica. Biomédica, 39 (2), 241-246 (2019).

10. Baird, F. J. et al. The Anisakis Transcriptome Provides a Resource for Fundamental and Applied Studies on Allergy-Causing Parasites. PLoS Negl Trop Dis, 10 (7), 1-17 (2016). 
11. Moneo, I., Carballeda-sangiao, N. \& González-muñoz, M. New Perspectives on the Diagnosis of Allergy to Anisakis spp. Curr Allergy Asthma Rep, 17, 27 (2017).

12. Puente, P. et al. Anisakis simplex: The high prevalence in Madrid (Spain) and its relation with fish consumption. Exp Parasitol, 118 (2), 271-274 (2008).

13. Jerončić, A. et al. Anisakis Sensitization in the Croatian fish processing workers: Behavioral instead of occupational risk factors? PLoS Negl Trop Dis, 14 (1), e0008038 (2020).

14. Mladineo, I., Poljak, V., Martínez-Sernández, V. \& Ubeira, F. M. Anti-Anisakis IgE Seroprevalence in the Healthy Croatian Coastal Population and Associated Risk Factors.PLoS Negl Trop Dis. 2014;8(2).

15. Anadon, A. M. et al. The Anisakis simplex Ani s 7 major allergen as an indicator of true Anisakis infections. Clin Exp Immunol, 156 (3), 471-478 (2009).

16. Cuellar, C. et al. Ani s 1 and Ani s 7 recombinant allergens are able to differentiate distinct Anisakis simplex-associated allergic clinical disorders. Arch Dermatol Res, 304 (4), 283-288 (2012).

17. Anadon, A. M. et al. Diagnosing human anisakiasis: Recombinant Ani s 1 and Ani s 7 allergens versus the UniCAP 100 fluorescence enzyme immunoassay. Clin. Vaccine Immunol, 17 (4), 496-502 (2010).

18. Castaño Díaz, F. Caracterización de la pesca artesanal en el consejo comunitario de La plata, Bahía Málaga, Buenaventura, Pacífico Colombiano (Pontificia Universidad Javeriana, 2012).

19. Rodríguez Salcedo, J., Hleap Zapata, J. I., Estrada, F., Clavijo Salinas, J. C. \& Perea Velasco, N. Agroindustria Pesquera en el Pacífico Colombiano: Gestión de Residuos Pecuarios en Sistema de Producción más Limpia (Palmira, 2011).

20. Daschner, A. Fish and Fish Oil In Health and Disease Prevention. In: Raatz SK, Bibus DM, editors. Fish and Fish Oil in Health and Disease Prevention [Internet]. Elsevier Inc; 2016. p. 341-53. Available from: http://dx.doi.org/10.1016/B978-0-12-802844-5.00031-2

21. Gamboa Delgado, E. M., Lopez Barbosa, N., Gomez Almeyda, E., Torres Alarcon, N. \& Castillo Morales, J. D. Determinacion del consumo de pescado en estudiantes universitarios de Bucaramanga, Colombia.Rev Salud Publica y Nutr. 2010;11(2).

22. Restrepo-Betancurt, L. F., Rodriguez-Espinosa, H. \& Valencia, D. Caracterización del consumo de pescado y mariscos en población universitaria de la ciudad de Medellín - Colombia. Rev Univ y Salud, 18 (2), 257-265 (2016).

23. Olivero, V. J., Caballero-Gallardo, K. \& Arroyo-Salgado, B. Nematode infection in fishfrom Cartagena Bay, North of Colombia. Vet Parasitol, 177 (1-2), 119-126 (2011).

24. Lin, A. H., Nepstad, I., Florvaag, E., Egaas, E. \& Van Do, T. An extended study of seroprevalence of antianisakis simplex IgE antibodies in norwegian blood donors. Scand J Immunol, 79 (1), 61-67 (2014).

25. Daschner, A. \& Cuéllar, C. Progress in Anisakis Allergy Research: Milestones and Reversals. Curr Treat Options Allergy, 7 (4), 457-470 (2020).

26. Daschner, A., Levsen, A. \& Cipriani, P. Cuéllar del Hoyo C. Anisakis allergy: unjustified social alarm versus healthy diet. Parasitol Res, 120 (2), 769-771 (2021). 
27. Valiñas, B. et al. Prevalence of and risk factors for lgE sensitization to Anisakis simplex in a Spanish population. Allergy Eur J Allergy Clin Immunol, 56 (7), 667-671 (2001).

28. Heffler, E. et al. High prevalence of Anisakis simplex hypersensitivity and allergy in Sicily, Italy. Ann Allergy Asthma Immunol [Internet]. 2016 Feb [cited 2016 May 23];116(2):146-50. Available from: http://www.ncbi.nlm.nih.gov/pubmed/26815707

29. de las Vecillas, L. et al. Analysis of Ani s 7 and Ani s 1 allergens as biomarkers of sensitization and allergy severity in human anisakiasis. Sci Rep [Internet]. 2020;10(1):1-10. Available from: https://doi.org/10.1038/s41598-020-67786-w 